\title{
KARAKTERISTIK FOURIER TRANSFORM INFRA RED DAN KEKUATAN BENTUR KOMPOSIT POLIESTER TAK JENUH BERPENGISI ABU SEKAM PADI PUTIH
}

\author{
Caroline Oktaviana Hutagalung, Maulida \\ DepartemenTeknik Kimia, FakultasTeknik, Universitas Sumatera Utara, \\ Jl. Almamater Kampus USU Medan 20155, Indonesia \\ Email: caroline_oktaviana@yahoo.com
}

\begin{abstract}
Abstrak
Penelitian ini bertujuan untuk mengetahui pengaruh komposisi dan ukuran partikel pengisi abu sekam padi putih sebagai pengisi terhadap karakterisrik Fourier Transform Infra Red (FTIR) dan sifat kekuatan bentur komposit poliester tidak jenuh. Komposit dibuat dengan metoda pencampuran terbuka dengan mencampurkan poliester dengan abu sekam padi putih dengan komposisi pengisi masing - masing 5, 10, 15 dan 20 (\% b/b) lalu ditambahkan $1 \%$ katalis metil etil keton peroksida. Parameter yang digunakan yaitu karakteristik FTIR dan kekuatan bentur. Hasil yang didapat yaitu peningkatan nilai kekuatan bentur untuk setiap komposisi dari pengisi abu sekam padi putih (ASPP). Nilai optimum kekuatan bentur dari komposit poliester berpengisi ASPP adalah $7031 \mathrm{~J} / \mathrm{m}^{2}$ dan 8297,333 J/m² untuk ukuran parikel maksimum 100 dan 250 mesh.
\end{abstract}

Kata kunci : abu sekam padi putih, komposit, ukuran partikel, poliester tidak jenuh, kekuatan bentur

\begin{abstract}
This study was aimed to investigate the effect of white rice husk ash as filler and particle size in Fourier Transform Infra Red (FTIR) characteristic and impact strength of polyester composites. The composites were made with open mixing method by mixing unsaturated polyester with white rice husk ash with the composition of 5,10, 15, and $20(\% \mathrm{w} / \mathrm{w})$ then added with $1 \%$ methyl ethyl ketone peroxide as catalizer. The parameters were characteristic of FTIR and impact strength. It was found that impact strength increased at each of composition of fillers white rice husk ash (WRHA). The optimum value of unsaturated polyester composite filled WRHA are $7031 \mathrm{~J} / \mathrm{m}^{2}$ and $8297,333 \mathrm{~J} / \mathrm{m}^{2}$ for particle size maximum 100 and $250 \mathrm{mesh}$.
\end{abstract}

Keywords : white rice husk ash, composite, particle size, unsaturated polyester resin, impact strength

\section{Pendahuluan}

Penggunaan polimer dan komposit dewasa ini semakin meningkat di segala bidang. Komposit berpenguat serat banyak diaplikasikan pada alat-alat yang membutuhkan material yang mempunyai dua perpaduan sifat dasar, yaitu kuat dan ringan. Pada saat ini komposit dengan material penyusun sintetis mulai beralih pada komposit dengan material penyusun dari bahan alami. Adapun penelitian tentang komposit polimer pada tahun - tahun terakhir lebih difokuskan pada pengisi alami daripada pengisi non alami [2]. Resin poliester dikenal sebagi resin yang paling sering digunakan untuk pembuatan komposit, karena memandang harganya yang murah, memiliki sifat fleksibel, mudah diproses, dibentuk dan memiliki sifat mekanik yang baik. Namun sifatnya yang rapuh membuat resin ini selalu dimodifikasikan dengan sejumlah bahan berpengisi [5]. Dalam pembuatan komposit, poliester telah banyak dimodifikasi dengan beberapa serat alami misalnya serbuk kayu, serat tandan kosong kelapa sawit (TKS), serat kayu kelapa sawit (KKS), serat buah pinang dan serat sintetik misalnya fiber glass. Pada penelitian yang telah dilakukan Ratri Pantoro pada tahun 2010, diperoleh bahwa variasi ukuran filler dan jenis filler berpengaruh terhadap kekuatan mekanik komposit [7].

Abu sekam padi biasanya dimanfaatkan sebagai pupuk, sebagai abu pencuci piring, dibuang atau dibiarkan saja tertimbun di atas tanah. Padahal jika dimanfaatkan sebagai filler komposit, seperti yang dijabarkan pada penelitian oleh Darwin Yunus
Nasution pada tahun 2006, dapat menghasilkan produk yang berkualitas dan dapat menaikkan nilai dari abu sekam padi itu sendiri [6].

\section{Teori}

Abu sekam padi ternyata mengandung senyawa silika cukup tinggi. Hasil analisa menunjukkan kandungan $\mathrm{SiO}_{2} 93 \%, \mathrm{pH}=8$, kadar air 2,70\%, luas permukaan butiran $68 \mathrm{~m}^{2} / \mathrm{gr}$ pada ukuran butir 325 mesh [6].

Abu sekam padi putih merupakan hasil dari sekam padi yang dibakar dengan suhu tinggi. Pembakaran sekam padi akan menghasilkan abu sekam padi putih dan hitam. Abu sekam padi hitam masih mengandung lignoselulosa, sedangkan abu sekam padi putih tidak mengandung lignoselulosa karena telah habis terbakar (pembakaran sempurna). Adapun matriks yang digunakan adalah poliester tak jenuh. Katalis yang digunakan dalam pembuatan komposit ini adalah metil etil keton peroksida (MEKP).

Poliester tak jenuh merupakan resin sintetik yang tersusun dari rantai lurus, yang dihasilkan dari reaksi glikol dengan asam difungsional seperti asam maleat, asam adipat, dll. Penggunaan umum dari poliester tak jenuh ini adalah untuk impregnasi fiber glass yang selanjutnya dicetak menjadi bentuk yang diinginkan dengan proses ikatan silang menjadi produk plastik yang bersifat lebih ringan dari pada aluminium, atau dapat lebih kuat dari baja [3]. 
Metil Etil Keton Peroksida adalah suatu bahan kimia yang dikenal dengan sebutan katalis. Katalis ini termasuk senyawa polimer dengan bentuk cair, berwarna bening. Fungsi dari katalis adalah mempercepat proses pengerasan (curing) pada bahan matriks suatu komposit. Semakin banyak katalis yang dicampurkan pada cairan matriks akan mempercepat proses laju pengeringan, tetapi akibat mencampurkan katalis terlalu banyak adalah membuatan komposit menjadi getas. Penggunaan katalis sebaiknya diatur berdasarkan kebutuhannya [4].

Komposit yang telah dibuat akan diuji sifat sifat mekanik dan karakteristiknya. Salah satunya adalah FTIR dan pengujian kekuatan bentur/impak.

Kekuatan impak adalah suatu kriteria penting untuk mengetahui ketegasan bahan atau ketahanan bahan terhadap daya dengan kecepatan tinggi (hantaman). Kekuatan impak suatu bahan polimer dapat diukur dengan menggunakan alat impact test [7].

Spektrofotometer infra merah terutama ditujukan untuk senyawa organik yaitu menentukan gugus fungsional yang dimiliki senyawa tersebut. Pola pada daerah sidik jadi sangat berbeda satu dengan yang lain, karenanya hal ini dapat digunakan untuk mengidentifikasi senyawa tersebut. Penetapan secara kualitatif dapat dilakukan dengan membandingkan tinggi peak (transmitansi) pada panjang gelombang tertentu yang dihasilkan oleh zat yang diuji dan zat yang standar. Dalam ilmu material analisa ini digunakan untuk mengetahui ada tidaknya reaksi atau interaksi antara bahan - bahan yang dicampurkan. Selain itu, nilai intensitas gugus yang terdeteksi dapat menentukan jumlah bahan yang bereaksi atau yang terkandung dalam suatu campuran [11].

\section{Metode}

\section{Bahan dan Alat}

Abu sekam padi yang digunakan diambil dari Kilang Padi Ginting yang berada di Jalan Tanjung Selamat, Kecamatan Sunggal. Sebelum digunakan abu sekam padi terlebih dahulu dikeringkan di bawah terik matahari atau dikeringkan di dalam oven selama \pm 2 jam, lalu diayak dengan ukuran ayakan 100 mesh dan 250 mesh, sedangkan poliester tak jenuh yang digunakan adalah seri Yukalac $157^{\circledR}$ BQTN-EX Series.

Pencampuran abu sekam padi putih dengan matriks poliester tak jenuh dilakukan di dalam beaker glass lalu diaduk menggunakan spatula. Komposit dicetak menggunakan cetakan plastisin diatas kaca dan pengujiannya menggunakan alat FTIR SHIMADZU IR-PRESTIGE 21 dan alat Impact Tester GOTECH.

\section{Proses Pembuatan Komposit Poliester Tak Jenuh Berpengisi Abu Sekam Padi Putih}

Abu sekam padi putih dikeringkan terlebih dahulu dibawah terik matahari atau diovenkan \pm 2 jam kemudian diayak / saring menggunakan ayakan 100 dan 250 mesh. Ukuran partikel 100 dan 250 mesh berarti ukuran partikel yang dapat keluar dari ayakan 100 dan 250 mesh. Maka abu sekam padi putih memiliki ukuran partikel maksimum 100 dan 250 mesh. Poliester tak jenuh (UPR) dicampur dengan abu sekam padi putih dengan komposisi pengisi 5, 10, 15 dan $20(\% \mathrm{~b} / \mathrm{b})$ lalu ditambahkan $1 \%$ katalis MEKP dan diaduk hingga rata. Komposit dicetak pada cetakan plastisin diatas kaca untuk pembuatan spesimen uji sesuai dengan ASTM. Spesimen dibiarkan selama 24 jam, lalu diangkat dari cetakan.

\section{Hasil dan Pembahasan}

\section{Karakteristik Fourier Transform Infra Red (FTIR)}

Gambar 1 menunjukkan hasil karakteristik FTIR dari poliester tak jenuh murni, ASPP dan komposit poliester tak jenuh berpengisi ASPP.

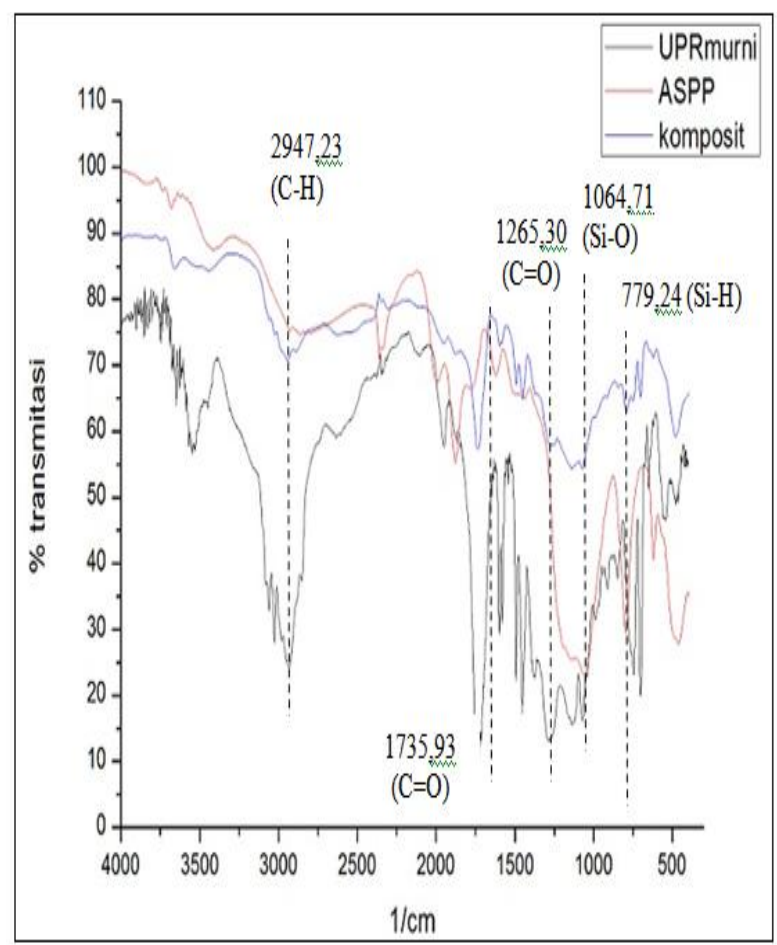

\section{Gambar 1. Karakteristik FTIR Poliester Tak Jenuh Berpengisi Abu Sekam Padi Putih}

Pada gambar 1 dapat kita lihat bahwa terjadi ikatan $\mathrm{Si}-\mathrm{H}$ pada komposit poliester tidak jenuh pada hasil karakteristik FTIR. Namun tidak ada reaksi yang dihasilkan antara pengisi abu sekam padi putih (ASPP) dengan matriks poliester tidak jenuh (UPR).

Ada tiga faktor yang mempengaruhi ikatan yakni: penjangkaran mekanik (mechanical anchoring), ikatan kimia antara serat alam dan resin dimana gugus hidroksil $(-\mathrm{OH})$ pada rantai belakang resin (poliester tidak jenuh) menyediakan sebuah daerah untuk mengadakan ikatan hidrogen terhadap serat alam yang mengandung banyak gugus hidroksil dalam struktur kimianya dan gaya molekular atraktif (gaya van der Waals dan ikatan hidrogen) [10]. 


\section{Kekuatan Bentur (Impact Strength)}

Gambar 2 menunjukkan pengaruh penambahan bahan pengisi abu sekam padi putih pada matriks poliester tak jenuh terhadap kekuatan bentur komposit untuk ukuran partikel 100 dan 250 mesh.

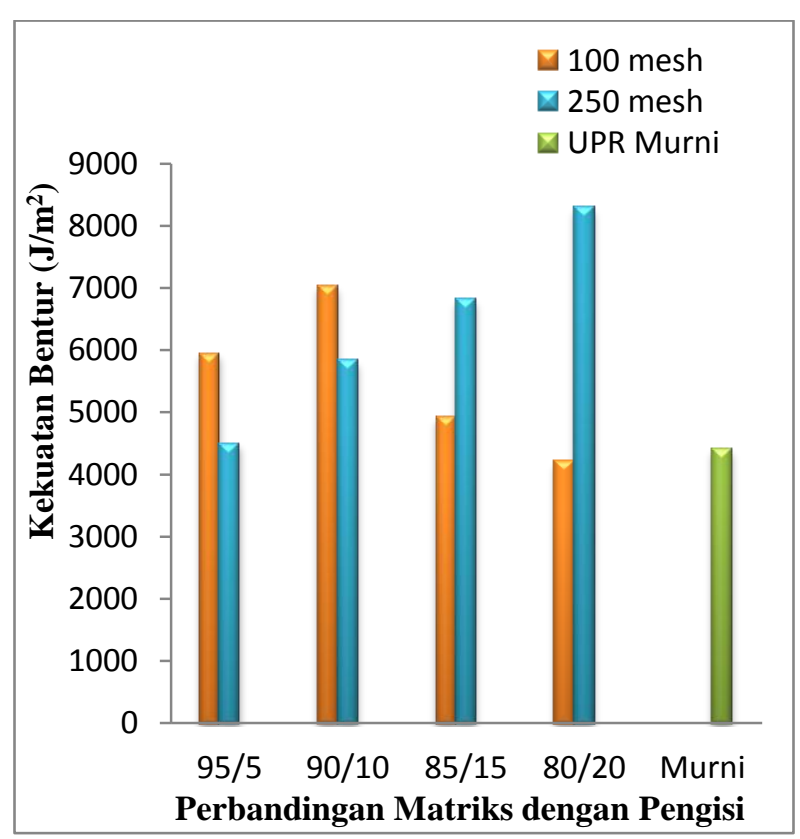

\section{Gambar 2. Pengaruh Kandungan dan Ukuran Partikel Bahan Pengisi ASPP Terhadap Kekuatan Bentur Komposit Poliester Tak Jenuh}

Dari Gambar 2 dapat dilihat bahwa nilai kekuatan bentur komposit poliester tak jenuh berpengisi abu sekam padi putih berada di atas nilai kekuatan bentur poliester tak jenuh murni. Rasio 95/5 artinya $95 \%$ matriks poliester tak jenuh dan $5 \%$ bahan pengisi ASPP. Peningkatan ini disebabkan karena penambahan ASPP (rasio 95/5, 90/10, 85/15 dan 80/20). Kecuali untuk ukuran partikel 100 mesh pada perbandingan $85 / 15$, nilai kekuatan benturnya mengalami penurunan. Penambahan pengisi ASPP tersebut akan menimbulkan interaksi dan mempengaruhi sifat - sifat dari komposit, termasuk kekuatan benturnya. Partikel dari ASPP yang cukup besar seperti ukuran partikel 100 mesh dan cenderung berikatan atau berkumpul membentuk algomerasi dalam kondisi lembab yang kemudian berinteraksi di daerah antarfasa sebagai pengisi dengan matriks poliester tak jenuh akan mempengaruhi kekuatan bentur komposit. Aglomerasi mengurangi kecocokan dari pengisi dan matriks [1]. Aglomerasi berarti penggumpalan bahan pengisi di dalam komposit. Dari gambar dapat juga kita lihat bahwa komposit poliester tak jenuh berpengisi ASPP dengan ukuran 250 mesh memiliki nilai kekuatan bentur lebih tinggi dari komposit poliester tak jenuh berpengisi ASPP dengan ukuran 100 mesh. Hal ini disebabkan oleh ukuran partikel yang lebih kecil akan memiliki luas permukaan yang lebih besar sehingga interaksi antara pengisi dan matriks akan semakin kuat, maka kekuatan benturnya pun akan meningkat dibandingkan ukuran partikel yang lebih besar.

\section{Kesimpulan}

Dari hasil uji FTIR didapat bahwa tidak terbentuk gugus baru pada komposit dan tidak adanya reaksi yang terjadi pada komposit UPR-ASPP. Meningkatnya kandungan bahan pengisi ASPP dalam komposit cenderung meningkatkan kekuatan benturnya pula. Nilai kekuatan bentur komposit dengan ukuran 250 mesh lebih tinggi dibandingkan dengan komposit dengan ukuran partikel 100 mesh.

\section{DaftarPustaka}

[1] Awal, A.S.M. Abdul dan Siew Kiat Nguong, A Short-Term Investigation On High Volume Palm Oil Fuel Ash (Pofa) Concrete, $35^{\text {th }}$ Conference on Our World In Concrete \& Structures: 25-27 August 2010, Singapore, 2010.

[2] Badri M, Muftil, Pengaruh Pembebanan Statik Terhadap Perilaku Mekanik Komposit Polimer Yang Diperkuat Serat Alam, Jurnal Dinamis Volume II No. 4, Universitas Riau, 2009.

[3] Cowd, M. A., Kimia Polimer, terjemahan oleh Firma H., ITB, Bandung, 1991.

[4] Justus Kimia Raya, Spesifikasi Produk UPR, http://justus.co.id Diakses pada 03 April 2013.

[5] Najmi, Noor, Sifat Mekanik dan Termal Komposit Hibrid Poliester Berpengisi Nano Zarah Tanah Liat dan Gentian Kenaf Diperkuat Getah Asli Cecair, Tugas Akhir, Fakultas Sains dan Teknologi, Universitas Kebangsaan Malaysia, 2010.

[6] Nasution, Darwin Yunus, Pengaruh Ukuran Partikel danberat Abu Sekam Padi Sebagai Bahan Pengisi Terhadap Sifat Kuat Sobek, Kekerasan dan Ketahanan Abrasi Kompon, Jurnal Sains Kimia Volume 10, Fakultas FMIPA, Universitas Sumatera Utara, 2006.

[7] Pantoro, Ratri, Studi Komparasi Sifat Mekanik Komposit Resin Poliester dengan Variasi Filler Serbuk Kayu, Tugas Akhir, Fakultas Teknologi Industri, Institut Teknologi Sepuluh November, Surabaya, 2010.

[8] Pavia, D. L., Lampman, G. M., Kriz, G. S., Introduction To Spectroscopy : A Guide for Students of Organic Chemistry, Singapore : Brooks/Cole Thomson Learning hal 26, 2001.

[9] Ratnasari, Pengolahan Cangkang Kelapa Sawit Dengan Teknik Pirolisis Untuk Produksi Bio-Oil, Skripsi, Teknik Kimia, Fakultas Teknik, Universitas Diponegoro, Semarang, 2011.

[10] Ray, D., Rout, J., Thermoset Biocomposites, Dalam Mohanty, A.K., Misra, M., Drzal, L.T., Natural Fibers, Biopolymers, And Biocomposites, CRC Press : U .S. A., 2005. 
Jurnal Teknik Kimia USU, Vol. 3, No. 1 (Maret 2014)

[11] Sunariyo, Karakteristik Komposit Termoplastik Polipropilena Dengan Serat Sabut Kelapa Sebagai Pengganti Bahan Palet Kayu, Tesis Magister, Sekolah Pascasarjana, USU, Medan, 2008. 